\title{
El control supra-constitucional de las leyes en Nicaragua. Una mirada desde la sentencia Yatama vs. Nicaragua
}

\author{
Byron G. Cárdenas Velásquez ${ }^{*}$ \\ Universidad Autónoma de Barcelona, España \\ byrocar@hotmail.com
}

Fecha de recibido: 06 de febrero de 2015/ Fecha de aprobación: II de mayo 2015

\section{Resumen}

Este artículo analiza el control jurisdiccional realizado por la Corte Interamericana de Derechos Humanos sobre algunas disposiciones constitucionales nicaragüenses en la sentencia Yatama vs. Nicaragua. En ese sentido, el artículo parte del conflicto normativo entre las normas internas impugnadas con la Convención Americana sobre Derechos Humanos. Además analiza la importancia de la jerarquía constitucional en los dos tipos de "control de convencionalidad"; uno previsto a ser practicados por la Corte Interamericana y el otro por los jueces internos. Por último, se analiza el estado actual de la implementación de las medidas legislativas establecidas en la sentencia, y la obligación de las autoridades internas frente al fallo interamericano.

\section{Palabras claves}

Control de Convencionalidad / Derecho Constitucional / Corte Interamericana de Derechos Humanos / Caso Yatama.

\footnotetext{
* Candidato a Doctor en Derecho Público por la Universidad Autónoma de Barcelona y Especialista en Derechos Humanos por la Universidad Complutense de Madrid. Ex-becario Rómulo Gallegos ante la Comisión Interamericana de Derechos Humanos y ex Oficial de Derechos Humanos ante la Misión de las Naciones Unidas en Sudan del Sur. Se ha desempeñado como consultor en temas de Derechos Humanos ante instituciones gubernamentales y agencias de la ONU en Nicaragua y ha publicado sobre temas de Derecho Constitucional y Derechos Humanos. Agradezco al Centro de Estudios y Documentación Latinoamericanos (CEDLA) de la Universidad de Ámsterdam, Países Bajos, por las facilidades prestadas para la realización de este artículo. Igualmente agradezco a Karlos Castilla por los comentarios realizados al texto.
} 


\section{Abstract}

This article analyses the judicial review applied by the Inter-American Court of Human Rights in the judgment Yatama vs. Nicaragua with respect to several of Nicaragua's constitutional provisions. It concentrates on the legal provisions that are in conflict with the American Convention on Human Rights. Moreover, the article addresses the relevance of Constitutional hierarchy by considering two types of "conventionality control"; one carried out by the Inter-American Court and the second one by Nicaragua's domestic courts. Finally, this article analyses the current implementation status of the legislative measures set out in the judgment, and the obligations of the domestic authorities with respect to this judgement.

\section{Keywords}

Conventionality control/ Constitutional law/ Inter-American Court of Human Rights / Yatama case.

\section{Tabla de contenido}

I. Introducción. I- El conflicto normativo deducido en el caso Yatama vs. Nicaragua. 2- La "convencionalidad" como parámetro de juicio de los actos y las normas internas. 3- El "control de convencionalidad" en el caso concreto. ¿Una nueva categoría de control supra-constitucional? 4- La relativización de la cláusula de supremacía constitucional. 5- Las reformas constitucionales ordenadas por la Corte Interamericana. 6- El parámetro del control interno en el cumplimiento de la sentencia ¿convencionalidad o constitucionalidad? 7- La violación continuada derivada del incumplimiento de la sentencia. 8- El control interno de convencionalidad como respuesta al incumplimiento de la sentencia interamericana. II. Conclusiones Generales. III. Referencias

\section{Bibliográficas.}

\section{Introducción}

La Corte Interamericana de Derechos Humanos (en adelante Corte Interamericana $\circ$ Corte IDH) ha fallado en tres casos contra Nicaragua ${ }^{4}$, pero en ninguno como en el caso Yatama vs. Nicaragua, de 23 de junio de 2005, ha puesto en entredicho la supremacía constitucional en el orden interno. A diferencia de los otros dos casos, en el caso Yatama la Corte Interamericana

\footnotetext{
${ }^{4}$ En ese sentido las sentencias de la Corte IDH contra Nicaragua en el caso Genie Lacayo (1997), Comunidad Mayagna (Sumo) Awas Tingni (2001) y Yatama (2005).
} 
declaró la incompatibilidad de ciertas disposiciones de la Ley Electoral (2000) y la Constitución Política (2014) (en adelante Constitución o Cn), con el derecho a la protección judicial y los derechos políticos reconocidos en la Convención Americana sobre Derechos Humanos (1969) (en adelante Convención Americana o $\mathrm{CADH})^{5}$.

El juicio de la normativa constitucional a la luz del estándar de protección garantizado en la Convención Americana vino a relativizar la cláusula de supremacía constitucional del artículo $182(\mathrm{Cn})$. La singularidad del asunto planteado supone en la etapa de cumplimiento de la sentencia, el ajuste de la normativa constitucional declarada incompatible con la Convención Americana para suprimir su contenido lesivo. Si bien el incumplimiento de tal medida legislativa no se aduce a razones del sistema legal interno, es posible que en el ámbito jurisdiccional doméstico se encuentre una respuesta alternativa e inmediata que allane el camino al cumplimiento de dicho fallo ajustado al canon de protección interamericano en ésta deducido.

El presente artículo es un análisis del control jurisdiccional ejercido por la Corte Interamericana sobre el derecho nicaragüense en cuestión: la Ley Electoral (2000) y la Constitución (20I4). Desde esa perspectiva, se aborda el parámetro normativo empleado para enjuiciar el derecho interno y la relevancia de la jerarquía normativa interna en el discernimiento de la Corte Interamericana. Por último, el análisis propuesto se centra en el conflicto normativo no superado y en el examen de algunas alternativas, para el cumplimiento del fallo interamericano; en este caso, bajo un ejercicio de ponderación del parámetro de constitucionalidad o del derivado del mismo tratado en el control de la citada normativa.

\section{El conflicto normativo deducido en el caso Yatama vs. Nicaragua}

Como se sabe, el caso se origina en la resolución del Consejo Supremo Electoral (en adelante CSE), de 15 de agosto de 2000, que negó la inscripción de los candidatos a alcalde del partido político regional indígena "Yapti Tasba Masraka Nanih Asla Takanka" (en adelante YATAMA); e impidió su participación en las elecciones municipales del 5 de noviembre de 2000 en las Regiones Autónomas del Atlántico Norte y del Atlántico Sur de Nicaragua. Aunque

\footnotetext{
${ }^{5} \mathrm{La}$ CADH fue firmada por Nicaragua el 22 de noviembre de 1969, pero ratificada y depositada el 25 de septiembre de 1979. Para consultar el estado de ratificaciones de la Convención Americana véase en: http://www.cidh.org/Basicos/Basicos3.htm
} 
YATAMA recurrió aquella decisión por medio de recursos de revisión y amparo ante el CSE y la Corte Suprema de Justicia (en adelante CSJ) respectivamente, estos terminaron confirmando la restricción inicialmente establecida por el CSE en aquella resolución 6 .

La relevancia de la resolución del CSE para el caso no era otra que la aplicación de la Ley Electoral (2000), en la que el órgano colegiado sustentó su resolución; particularmente, debido a la aplicación de los nuevos requisitos establecidos para participar en los procesos electorales. Los requisitos exigían a los contendientes: el deber de presentar el $3 \%$ de firmas de ciudadanos identificados con el número de cédula, excepto en el caso de los partidos políticos que en las últimas elecciones nacionales hubieren obtenido un mínimo de $3 \%$ de los votos válidos en las elecciones presidenciales, para presentar los candidatos (arto.77.7); la exigencia de inscribir candidatos en al menos en el ochenta por ciento $(80 \%)$ de los municipios y al menos el ochenta por ciento $(80 \%)$ del total de las candidaturas (arto. 82); y el deber de inscribir candidatos para todas las elecciones y cargos a que se refiere el artículo I de dicha Ley (arto.80) (Corte IDH, Yatama vs. Nicaragua, párr. I24.5I.).

El incumplimiento de aquellos requisitos por parte de YATAMA dio lugar a su exclusión de las elecciones municipales; no obstante, la aplicación de los criterios legales puso en perspectiva la compatibilidad del contenido restrictivo de la Ley Electoral (2000) con la garantía de los derechos políticos reconocidos en el artículo 23 de la CADH. Adicionalmente, YATAMA también se vería impedido de impugnar la decisión del CSE que le afectaba, en razón del carácter inimpugnable de las decisiones del CSE en materia electoral 7 ; reconocido en el último párrafo del artículo 173 de la Constitución (2014), el 53.4 de la Ley de Amparo (20I3), y el párrafo segundo del artículo I de la Ley Electoral (2000); lo

${ }^{6}$ Previo al amparo denegado por la Sala Constitucional, YATAMA había interpuesto un amparo administrativo ante la Sala de lo Civil y Laboral del Tribunal de Apelaciones de la Circunscripción Atlántico Norte, que mandó a suspender el acto, pero que luego fue invalidado por la Sala Constitucional. (Corte IDH, Yatama vs. Nicaragua, párr. 2 y numeral 54, 55 y 61 del párr. 124.)

${ }^{7}$ El artículo 76 de la Ley Electoral (2000) solo prevé el recurso de amparo contra las resoluciones definitivas sobre partidos políticos que dicte el CSE. Es decir, es aplicable contra las decisiones de carácter administrativa sobre los partidos políticos, según la jurisprudencia de la misma Sala Constitucional, sentencia No.205, de 25 de octubre de 2000 (citada en Yatama v. Nicaragua, párr. 124.61). En ese mismo sentido, véase también la sentencia No. 156, de la Sala Constitucional de la CSJ, de 20 de noviembre de 2002, que ampara al Partido Conservador ante la decisión administrativa del CSE que cancelaba su personalidad jurídica. 
cual daría lugar al examen de su posible contrariedad con la protección judicial reconocida en la Convención Americana.

El examen inicial de aquellas disposiciones internas a la luz de la Convención Americana fue planteado primeramente por la Comisión Interamericana de Derechos Humanos (en adelante Comisión Interamericana) en el informe de fondo del caso $^{8}$, quien dejó a la vista la contradicción de las disposiciones constitucionales con el texto internacional. En consecuencia, la Comisión Interamericana estableció una serie de recomendaciones relativa a la necesidad de reformar y suprimir el contenido restrictivo de ciertas disposiciones de la Ley Electoral (2000) y la Constitución (20/4). Por una parte, para garantizar la participación política de los pueblos indígenas de acuerdo a sus formas tradicionales de organización, sus usos y costumbres; $y$, por otra parte, para crear un recurso efectivo y sencillo que permita impugnar las resoluciones del CSE (Corte IDH, Yatama vs. Nicaragua, párr.7).

El conflicto normativo sostenido por la Comisión Interamericana luego sería sostenido y confirmado por la Corte IDH en la citada sentencia de fondo, en este caso bajo un control judicial propio de su naturaleza jurisdiccional internacional; que dio lugar a interpelar al Estado para que reparara los daños derivados de las violaciones a los derechos humanos constatadas. De ese modo, el control jurisdiccional supranacional practicado sobre las disposiciones impugnadas de la Ley Electoral (2000) y de la Constitución (2014), supuso para Nicaragua la materialización del parámetro de "convencionalidad" en el enjuiciamiento de su propia normativa constitucional, implícita desde la aceptación` de la competencia contenciosa de la Corte IDH'10.

\footnotetext{
${ }^{8}$ Sobre el informe de fondo de la CIDH véase el Informe $\mathrm{N}^{\mathrm{o}} 24 / 03$, de 4 de marzo de 2003.

${ }^{9}$ Nicaragua aceptó la competencia contenciosa de la Corte interamericana el 12 de febrero de 1991, para todos los casos relativos a la interpretación o aplicación de la Convención Americana. Sin embargo, en el Acuerdo Gubernativo Número 3-90, aprobado el 25 de Abril de 1990, Gaceta No 94 del 17 de Mayo de 1990, dejó constancia de que la declaración de aceptación "comprende solamente hechos posteriores o hechos cuyo principio de ejecución sean posteriores a la fecha de depósito de esta declaración ante el Secretario General de la Organización de los Estados Americanos".

${ }^{10}$ Para conocer de "cualquier caso" relativo a la interpretación y aplicación de la Convención Americana y demás instrumentos interamericanos (arto. 62.3 CADH), bajo el sistema de peticiones individuales regulado en el artículo 44 de la CADH.
} 


\section{La "convencionalidad" como parámetro de juicio de los actos y las normas internas}

Como se sabe, la aceptación de la competencia contenciosa de la Corte IDH por cualquier Estado parte de la CADH implica la sesión de cuotas de soberanía en el ámbito de protección de los derechos humanos reconocidos a nivel regional; bien para garantizar dichos derechos mediante medias legislativas, como para suprimir aquellas que amenazan su garantía. En ese sentido, cuando un Estado es demandado por violaciones a los derechos reconocidos en la $\mathrm{CADH}$ u otro tratado interamericano, también aceptado y ratificado por un Estado, pasa a ser examinado a la luz de la normativa interamericana. Los actos y disposiciones enjuiciables ante la Corte IDH pueden ser resoluciones y actos administrativos y cualquier disposición del derecho interno, inclusive la misma Constitución Política, cuando contravienen el sentido y objeto del tratado (Corte IDH, OC-4/84, párr.2I).

Así las cosas, en el caso que nos ocupa el examen de la normativa interna impugnada tuvo como parámetro la compatibilidad la Convención Americana, en virtud de las obligaciones internacionales asumidas por Nicaragua desde la ratificación y la aceptación de la competencia contenciosa de la Corte IDH; pero también por razón de la naturaleza subsidiaria del sistema de garantía interamericano implícito en el requisito del agotamiento previo de los recursos internos". En todo caso, porque al aplicar e interpretar la CADH la Corte Interamericana, como máximo intérprete, vela por salvaguardar el objeto y fin que persigue el tratado sobre cualquier disposición o acto de orden interno que le contradiga.

En la actualidad la Corte Interamericana ha asumido un discurso constitucional más intenso en el despliegue de su función judicial, bajo la terminología "control de convencionalidad" (García Roca et al., 2012); cuyo surgimiento se ubica en los votos razonados del ex juez interamericano Sergio García Ramírez a las sentencias Myrna Mack Chang vs. Guatemala, Tibi vs. Ecuador, López Álvarez vs. Honduras y Vargas Areco vs. Paraguay (Pelayo, 2013). Así, según García Ramírez,

\footnotetext{
${ }^{11}$ En vista de la exigencia del agotamiento previo de los recursos internos que consagra el carácter supletorio de su jurisdicción (arto.46.1.a de la CADH), su actuación solo se verá habilitada cuando en el orden interno no se hayan protegido los derechos convencionales de acuerdo al estándar interamericano.
} 
bajo la jurisdicción contenciosa la Corte Interamericana "analiza los actos que llegan a su conocimiento en relación con normas, principios y valores de los tratados [...]", y de la misma forma que los tribunales constitucionales "controlan la 'constitucionalidad', el tribunal internacional de derechos humanos resuelve acerca de la 'convencionalidad' de esos actos"' 2 .

Tal analogía ha llevado a estimar que la jurisdicción de la Corte IDH encuentra cierta correspondencia con la de los sistemas concentrados de constitucionalidad (Hitters, 2009). Por otra parte, se ha justificado que la asimilación de la Corte IDH de ciertas funciones constitucionales puede ser comprendida en la asunción de un destacado rol "en la construcción de una cultura de los derechos ante la debilidad de las tradiciones constitucionales nacionales a la hora de su garantía" (García Roca et al, 20I2, p.88). Una circunstancia, en palabras del juez Mac-Gregor (2010), que puede estar dando lugar a la creación de un auténtico ius constitutionale commune en las Américas ${ }^{13}$.

Ciertamente, en la expresión "control de convencionalidad" la Corte Interamericana exterioriza la asimilación del esquema de control de constitucionalidad previsto en los sistemas concentrados o continentales, típico de algunas constituciones europeas, como la austriaca, que prevé el control judicial de los actos y leyes en un solo órgano: el Tribunal Constitucional (Hitters, 2009). Por ello que en la doctrina se le haya denominado "control concentrado de convencionalidad" (Mac-Gregor, 2010)14.

Así como un Tribunal Constitucional tiene como parámetro de control judicial la Constitución Política, la Corte IDH examina la compatibilidad de la legislación interna y actos impugnados con el estándar fijado en la Convención Americana, los demás tratados interamericanos y su jurisprudencia. Por tanto, cuando la Corte IDH declara la incompatibilidad de la norma enjuiciada con la CADH se asume su 'inconvencionalidad' $\circ$ bien su convencionalidad cuando se haya constatado o no su contradicción con la CADH u otros tratados interamericanos. $Y$ del mismo modo en que las sentencias de un Tribunal Constitucional terminan atando a los poderes públicos, las de la Corte

\footnotetext{
${ }^{12}$ Voto razonado del juez Sergio García Ramírez a la sentencia Tibi vs. Ecuador, de 7 de septiembre de 2004, párr.3.

${ }^{13}$ Voto razonado del juez Ferrer Mac-Gregor a la sentencia Cabrera García y Montiel y Flores vs. México, de 26 de noviembre de 2010, párrs. 85 y ss.

${ }^{14}$ En esos mismos términos se han referido otros autores como Hitters $(2009,2006)$, Sagües (2010, 2011), García Ramírez (2011), Bazán (2012), Brewer-Carías (2012), Pelayo (2013).
} 
Interamericana también los atan, incluso, a los mismos tribunales constitucionales en una suerte de jurisdicción supranacional (Hitters, 2006).

La deducción de aquel paralelismo, ciertamente, no ha significado una ampliación de las potestades jurisdiccionales de la Corte Interamericana, pues antes del arribo de aquella terminología ya ejercía un "control de convencionalidad"; teniendo como parámetro de juicio la compatibilidad de los actos y normas internas con la CADH y demás tratados (Sagües, 20I I; Hiters, 2009). Así se infiere que al haber empleado un parámetro de "convencionalidad" en Yatama vs. Nicaragua, la Corte también realizó, en sus propios términos, un "control de convencionalidad" en el examen de la compatibilidad de la Ley Electoral (2000), la Constitución (2014) y la resolución del CSE con el CADH, aunque no lo haya expresado así en la sentencia.

\section{El "control de convencionalidad" en el caso concreto ¿Una nueva categoría de control supra-constitucional?}

Como se ha indicado, las cuestiones violatorias a la Convención Americana planteadas en el caso Yatama vs. Nicaragua requirió el examen de la compatibilidad de ciertas disposiciones de la Ley Electoral (2000) con el estándar mínimo establecido en la Convención Americana. Propiamente, sobre los requerimientos exigidos para participar en los procesos electorales -el porcentaje de firmas (3\%) (arto. 77.7) $)^{15}$, la inscripción de los candidatos en el $80 \%$ de municipios a nivel nacional (arto. 82)- que sirvieron de base para la resolución del CSE (Yatama vs. Nicaragua, párr. 15I). Como también la exigencia a YATAMA de constituirse en un partido político para poder participar en el procesos electoral (arto. 7I).

No obstante, la negativa de la Sala Constitucional de la CSJ de amparar a YATAMA ante la resolución del CSE, en virtud del carácter inimpugnable de sus resoluciones en materia electoral, regulado en el último párrafo del artículo 173 Cn (2014), el 53.4 de la Ley de Amparo (2013), y el artículo I de la misma Ley

15 La Ley Electoral (2000), de rango constitucional, aprobada el 19 de enero del 2000, suprimió la participación en las elecciones por medio de "las asociaciones de suscripción popular" que contenía las leyes electorales de 1990 y 1996, bajo las cuales YATAMA participó en las elecciones regionales de 1990, 1994, y1996. Desde ese punto de vista, dicha Ley restringió la participación en los procesos electorales a la constitución de partidos políticos. 
Electoral (2000); conllevó la necesaria verificación de la compatibilidad del carácter no recurrible de tales resoluciones del CSJ con el derecho a un recurso sencillo y rápido reconocido en el 25.I de la CADH.

La Corte Interamericana constató que la resolución del CSE impidió el ejercicio del derecho de participación política a los miembros de YATAMA, en franca violación al estándar mínimo de garantía judicial establecido en la Convención Americana; pero también constató la contrariedad o "inconvencionalidad" de las normas constitucionales en cuestión. Así, respecto a la resolución del CSE declaró la violación de las garantías judiciales (arto.8.I) y el deber de respetar los derechos (arto.I.I) de la Convención Americana, por carecer de elementos básicos de la fundamentación y porque no fue notificada al partido político (Yatama vs. Nicaragua, párr.164).

Con mayor rigurosidad se expresó en relación al contenido del último párrafo del artículo 173 constitucional replicado en la Ley Electoral (2000) y Ley de Amparo $(2013)^{16}$, ambas de carácter constitucional pero jerárquicamente inferiores a la Constitución (20/4) ${ }^{17}$, que declara no recurrible las decisiones en materia electoral del CSE. Para tales efectos, la Corte Interamericana declaró la contravención de esas normas con el derecho a un recurso rápido y sencillo consagrado en el 25.I de la $\mathrm{CADH}^{18}$; en virtud de que bajo su potestad jurisdiccional 19 el CSE resuelve sobre una materia que también afecta ciertos derechos humanos. La imposibilidad de recurrir tales decisiones ante otra instancia las sustrae de algún control jurisdiccional, lo que resulta inaceptable en el sentido de un Estado de Derecho y del objeto y fin de la CADH (Yatama vs. Nicaragua, párr. 169). Adicionalmente, la Corte Interamericana agregó:

${ }^{16}$ De acuerdo a la más reciente reforma parcial a la Constitución Política (Supra Nota 31), la Ley de Amparo (2013) será sustituida por la nueva Ley de Justicia Constitucional (2014) creada en dichas reformas. No obstante, "La Ley de Amparo continuará en vigor hasta que entre en vigencia la Ley de Justicia Constitucional" (Artículo transitorio Cuadragésimo Noveno).

17 A pesar de que la Ley Electoral (2000) "tiene rango constitucional no es la constitución misma y como tal no debe ser contravenida" por ésta. Véase en el Considerando I de la sentencia No.136, de 30 de octubre de 2002, de la Sala Constitucional de la CSJ.

${ }^{18}$ La Constitución (2014) (arto. 173 in fine) y la Ley de Amparo (2013) (arto. 51.5) disponen que respecto de las resoluciones del CSE en materia electoral "no habrá recurso alguno, ordinario ni extraordinario". La Ley Electoral (2000) únicamente prevé recurribles de amparo las decisiones del CSE sobre materia de partidos políticos (arto.176).

${ }^{19}$ Artículo 10 de la Ley Electoral (2000). 
"Si bien la Constitución de Nicaragua ha establecido que las resoluciones del Consejo Supremo Electoral en materia electoral no son susceptibles de recursos ordinarios o extraordinarios, esto no significa que dicho Consejo no deba estar sometido a controles judiciales, como lo están los otros poderes del Estado" (párr. 174).

En ese sentido, si la resolución del CSE podía incidir directamente en el ejercicio de los derechos políticos de YATAMA mayor fuerza cobraba la exigencia de su protección judicial. La deficiente protección verificada en la Constitución (20I4), Ley Electoral (2000) y Ley de Amparo (2013), devino en la declaración de responsabilidad internacional de Nicaragua. La situación violatoria constatada exigió, como consecuencia, la adecuación normativa -reforma constitucionalcon el canon de protección contenido en la Convención Americana; para crear un recuso sencillo y rápido contra las resoluciones del CSE, según la obligación genérica de la disposición 2 de la CADH (Yatama vs. Nicaragua, párrs. I74- 176.).

No obstante, la ausencia de protección especial de los pueblos indígenas en el reconocimiento de los derechos políticos del artículo 23 de la Convención Americana, planteó su interpretación "a la luz de las disposiciones normativas de la Constitución Política, del Estatuto de Autonomía de la Costa Atlántica y de la Ley de Municipios" de mayor protección (Yatama vs. Nicaragua, párr. 178.d). Así, sustentado en el principio pro homine (arto.29.b de CADH), la Corte Interamericana examinó la compatibilidad de la Ley Electoral (2000) con el tratado, teniendo como referencia la protección de los derechos de los pueblos indígenas regulada en los artículos 5, 49,89 y 180 de la Constitución (2014) y el artículo 11.7 del Estatuto de Autonomía de las Regiones de la Costa Atlántica (1987) (Yatama vs. Nicaragua, párr.205). A la luz de la cual, terminó confirmando la contradicción de la ley impugnada con la $\mathrm{CADH}$, pero también vislumbrando una antinomia constitucional.

El control jurisdiccional supranacional puso en perspectiva los márgenes del Estado para garantizar los derechos políticos de los pueblos indígenas, en todo caso porque los requerimientos establecidos en la Ley Electoral (2000) comprometieron el ejercicio de tales derechos a los candidatos propuestos por YATAMA. Primero, por su inconformidad con los principios de legalidad, necesidad y proporcionalidad; segundo, porque su exigencia desbordó los criterios razonables de atender a un propósito útil y oportuno que la tornara necesario para satisfacer un interés público imperativo; $y$, por lo tanto, proporcional a ese objetivo (Yatama vs. Nicaragua, párr.206). Y, por último, porque la ambigüedad de la norma favorecía su aplicación arbitraria y 
discrecional que daba lugar a intromisiones indebidas a la participación política de los ciudadanos (Yatama vs. Nicaragua, párr.212).

Asimismo, considerando que la $\mathrm{CADH}$ se configura en un sistema de participación política abierto y no restringido a ciertas formas de organización, como los partidos políticos; la Corte Interamericana estimó que ello favorecía el impulso de candidaturas para cargos de elección popular bajo otras formas de organización, de tradiciones diversas y ordenamientos especiales; concretamente de grupos específicos de la sociedad (párr. I I5). Y pese a que el párrafo segundo del artículo 7l de la Ley Electoral $(2000)^{20}$ trató de preservar la participación de las organizaciones indígenas bajo la forma tradicional de organización social a que refiere el párrafo tercero del artículo 5 constitucional, lo cierto es que el requisito de la conformación de partidos políticos terminó siendo exigido a YATAMA.

La constatación de la desproporción de la medida legal y el reconocimiento implícito del gobierno (Yatama vs. Nicaragua, párr.210), allanó el camino a la Corte IDH para sentar un precedente en el tema. Al respecto dicho tribunal sostuvo:

"La restricción de participar a través de un partido político impuso a los candidatos propuestos por YATAMA una forma de organización ajena a sus usos, costumbres y tradiciones, como requisito para ejercer el derecho a la participación política, en contravención de las normas internas que obligan al Estado a respetar las formas de organización de las comunidades de la Costa Atlántica, y afectó en forma negativa la participación electoral de dichos candidatos en las elecciones municipales de 2000" (párr.218).

La intromisión al derecho a ser elegido bajo aquella exigencia no justificó su utilidad y oportunidad ni la satisfacción de un interés público imperativo, por consiguiente, configuró "una restricción indebida al ejercicio de un derecho político, que implica un límite innecesario al derecho a ser elegido" (Yatama vs. Nicaragua, párr.219). Bajo similares criterios la Corte IDH también estimó la "restricción desproporcionada" del requisito de artículo 82 de la Ley Electoral (2000), que sustentó la resolución del CSE, en razón del requisito de presentar candidatos en "al menos en el $80 \%$ de los municipios de la respectiva

\footnotetext{
${ }^{20}$ Así establece: "en el caso de las organizaciones indígenas para que conformen los partidos regionales su propia forma natural de organización y participación".
} 
circunscripción territorial y respecto del $80 \%$ del total de las candidaturas" (Yatama vs. Nicaragua, párrs.22I y 222).

Como ya lo había sostenido para las demás disposiciones cuestionadas, la Corte IDH constató que el contenido discriminatorio del artículo 82 no tomaba "en cuenta que la población indígena y étnica es minoritaria en la RAAS [Región Autónoma del Atlántico Sur], ni que habría municipios en los que no se contaría con apoyo para presentar candidatos o no se tendría interés en buscar dicho apoyo" (Yatama vs. Nicaragua, párr.223).

En ese sentido, hay que decir que el control jurisdiccional de las normas constitucionales en este caso no provoca ninguna extrañeza en la forma en que la Corte IDH ha examinado el derecho interno. En efecto, en el caso La última Tentación de Cristo (Olmedo Bustos y otros) vs. Chile (2006) y en los dos casos Boyce (2007) y Dacosta Cadogan (2009) contra Barbados, por ejemplo, dichos estados también se vieron compelidos a modificar ciertas disposiciones de sus constituciones políticas para compatibilizarlas con la CADH (Mac-Gregor \& Pelayo, 2012). Por otra parte, cabe aclarar que tal criterio de enjuiciamiento no significa que el régimen de mínimo de garantía siempre se encuentre en la norma interamericana; pues, como ya se ha mencionado, la Corte IDH terminó por interpretar el artículo 23 de la CADH a la luz de ciertas disposiciones de la Constitución (2014), del Estatuto de Autonomía de la Costa Atlántica (1987) y de la Ley de Municipios (20/2), que brindaban una protección especial a los pueblos indígenas hasta ese entonces no concebida en el tratado.

En esos términos, es indefectible que bajo el denominado "control concentrado de convencionalidad" se colige la existencia de un control supra-constitucional de las normas internas; en todo caso por la supraconstitucionalidad que la CADH adquiere en el ordenamiento jurídico doméstico (Sagües, 20I0), en situaciones particulares como la del caso analizado. De esa manera, aunque el texto constitucional no le conceda tal jerarquía al tratado ${ }^{21}$, la $\mathrm{CADH}$ puede terminar imponiéndose ante la Constitución por virtud del examen de compatibilidad que la Corte IDH realiza bajo su jurisdicción contenciosa; básicamente porque ante su sede el derecho interno es considerado como un hecho más a ser probado (Abreu, 1999), y de la jerarquía interna de los normas no adquiere la relevancia que sí tiene en el orden doméstico.

\section{La relativización de la cláusula de supremacía constitucional}

\footnotetext{
${ }^{21}$ El artículo 46 de la Constitución (2014) ubica a la CADH al mismo orden jerárquico de la Constitución.
} 
El artículo I82 constitucional establece que "[l]a Constitución Política es la carta fundamental de la República; las demás leyes están subordinadas a ella. No tendrán valor alguno las leyes, tratados, decretos, reglamentos, órdenes o disposiciones que se le opongan o alteren sus disposiciones". No obstante, tal afirmación debe ser matizada y leída en concordancia con los criterios jurisprudenciales de la Sala Constitucional de la CSJ, que ha interpretado que los tratados sobre derechos humanos mencionados en el artículo 46 constitucional, entre otros, la Convención Americana, están reconocidos bajo el mismo rango constitucional22.

De ese modo, se entiende que los tratados, convenciones y las declaraciones sobre derechos humanos deben exceptuarse del régimen de jerarquía previsto en el 182; y la alusión a los tratados internacionales en tal disposición aplica a tratados de otra naturaleza. En ese escenario, se considera que en el supuesto de antinomias entre disposiciones de la CADH y la Constitución Política, por ejemplo, la excepción a la cláusula de jerarquía normativa es también aplicable si por virtud del principio pro homine23; la CADH termina imponiéndose sobre la Constitución, por brindar una mayor protección que la reconocida constitucionalmente.

Así, entonces, se puede sostener que la cláusula de supremacía constitucional del 182 puede ser exceptuado cuando la exigencia del respeto y garantía de los derechos humanos impone un estándar de protección mayor que el reconocido domésticamente. Ante lo cual tendría plena cabida la aplicación preferente de cualquiera de los tratados reconocidos en el 46 constitucional, y los ratificados por Nicaragua pero excluidos de tal lista. En esos términos, cualquier judicial u autoridad interna estaría obligado a impedir una transgresión del estándar mínimo de protección previsto en un tratado, y de ser el caso, apoyarse en la jurisprudencia interamericana para aplicar la CADH de forma preferente. En caso contrario, el mecanismo subsidiario de protección regional se vería habilitado para conocer y resolver el supuesto de violación, tal y como ocurrió en el caso concreto de Yatama vs. Nicaragua.

\footnotetext{
${ }^{22}$ Véase las sentencias de la Sala Constitucional No. 57/2010, del día dos de marzo del año dos mil diez y la sentencia No. 78/2010, del día diez de marzo del año dos mil diez.

${ }^{23}$ Reconocido implícitamente en el artículo $5 \mathrm{Cn}$.
} 
En ese escenario, los contornos de la actividad jurisdiccional de la Corte IDH no se ven limitado por la jerarquía normativa de las leyes domésticas impugnadas ni por el estatus legal que pueda adoptar la $\mathrm{CADH}$ en cada Estado. En todo caso, porque las leyes internas ${ }^{24}$ son consideradas en el Derecho internacional como un hecho más que expresa la voluntad de los Estados y que "debe ser probado" por las partes que las aleguen (Abreu, 1999).

Por tanto, la sentencia interamericana aludida implica, de cara al valor supremo de la Constitución nicaragüense (182 Cn) y del valor interno de la CADH (46 $\mathrm{Cn}$ ), una una lectura más amplia del contenido de dichas disposiciones en conjunción con los principios internacionales; no para establecer otro orden de jerarquía sino para comprender que los derechos reconocidos en el texto constitucional se configuran en un sentido abierto a los tratados internacionales sobre la materia; y que en determinadas circunstancias estos pueden poner en entredicho la supremacía constitucional. Lo cual, tampoco, debe significar la invalidación de dicha cláusula, sino su excepción en el ámbito de protección de derechos; pues frente a otras normas y tratados de otra naturaleza ésta se mantendría invariable.

Así, se considera que la supremacía constitucional se ve cuestionada no solo por la manifiesta irrelevancia de su jerarquía en el examen, discernimiento y constatación de las violaciones al tratado ante la Corte IDH; sino también en virtud del enjuiciamiento de la normativa constitucional a la luz del tratado bajo el teorema del "control interno de convencionalidad"; que autorizaría al judicial - cualquier autoridad interna para inaplicar una disposición constitucional contraria a la CADH. En esos escenarios, la obligación estatal convergería en la compatibilización u armonización de los estándares de protección interno con el sistema subsidiario, como del contenido de las disposiciones constitucionales impugnadas o estimadas contrarias con la $\mathrm{CADH}$; a fin de garantizar ejercicio de los derechos reconocidos internacionalmente, como se verá más adelante.

\footnotetext{
${ }^{24}$ De acuerdo con los criterios interamericanos la expresión "leyes internas" del artículo 64.2 de la $\mathrm{CADH}$ incluye además las propias constituciones políticas (Opinión Consultiva OC-4/84, párr. 21).
} 


\section{Las reformas constitucionales ordenadas por la Corte Interamericana}

La Corte IDH estableció una serie de medidas de reparación ${ }^{25}$, entre las cuales sobresalen las de carácter positivo destinadas a evitar la repetición de los hechos (Yatama vs. Nicaragua, párrs.254-260). Bajo estas últimas la Corte IDH declaró el deber de Nicaragua de adoptar las medidas legales para compatibilizar las disposiciones de la Ley Electoral (2000) y la Constitución (20l4) con la Convención Americana en dos sentidos.

Por una parte, estableció el deber de Nicaragua para "establecer un recurso judicial sencillo, rápido y efectivo que permita controlar las decisiones del [CSE]" (Yatama vs. Nicaragua, punto resolutivo 9). Aunque la Corte IDH no indicó expresamente las normas que debían reformarse, implícitamente se refiriera a los artículos 173 in fine de la Constitución (2014), el artículo 53.4 de la Ley de Amparo (2013) y el I de la Ley Electoral (2000); cuya incompatibilidad con el derecho a un recurso sencillo y rápido reconocido en el 25.I de la $\mathrm{CADH}$ ya había sostenido en los fundamentos de la sentencia (Yatama vs. Nicaragua. párrs. 171-76) ${ }^{26}$.

Por otra parte, la Corte IDH estimó necesario que se adecuaran los requisitos establecidos en la Ley Electoral (2000), para aclarar las ambigüedades respecto a las circunstancias en que aquellos pueden ser incumplidos y con ello evitar interpretaciones extensivas e intromisiones arbitrarias en el ejercicio de los derechos políticos. Asimismo, estableció el deber de adoptar las "medidas necesarias para que los integrantes de las comunidades indígenas y étnicas puedan participar en los procesos electorales en forma efectiva y tomando en cuenta sus tradiciones, usos y costumbres, en el marco de la sociedad democrática" (Yatama vs. Nicaragua, párr.259). En otras palabras, esto equivalía a reformar el requisito para conformar partidos políticos y participar en los procesos electorales, también exigido a las organizaciones políticas indígenas; y compatibilizar el artículo 7I la Ley Electoral (2000) con el 5 constitucional.

\footnotetext{
${ }^{25}$ Por ejemplo, publicar la sentencia en radios de difusión nacional y medios escritos, pagar una indemnización y las costas del juicio a YATAMA. Véase los puntos resolutivos de la sentencia Yatama vs. Nicaragua.

${ }^{26}$ En tal sentido, la sentencia estipula la obligación de "[derogar] las normas que impidan la interposición de ese recurso" (y 254).
} 


\section{El parámetro de cumplimiento de la sentencia ¿convencionalidad o constitucionalidad?}

Como se ha explicado, la Corte IDH interpretó el alcance de los derechos políticos reconocidos en la CADH a la luz del régimen jurídico especial nicaragüense, que ofrecía una mayor cobertura que el tratado. Sin embargo, en relación a la inimpugnabilidad de las resoluciones del CSE en materia electoral la Corte IDH se circunscribió al contenido de la CADH y su jurisprudencia, para declarar la contrariedad de tal disposición constitucional con la Convención. Las variantes empleadas por la Corte Interamericana para interpretar y aplicar el citado tratado, pudo haber dejado a la vista también un doble rasero constitucional y convencional- a tomar en cuenta al momento de realizar los ajustes legales establecido en la sentencia.

Lo anterior no desdice, en cualquiera de los casos, la obligación de resultado que emana de la sentencia interamericana; cuyo efecto es producto del compromiso internacional de Nicaragua de cumplir el fallo, como consecuencia de la aceptación de la jurisdicción contenciosa de la Corte IDH. El análisis propuesto, entonces, se centra en desentrañar el parámetro normativo para ajustar el contenido declarado lesivo y no en la obligación de cumplir la sentencia interamericana; la cual no queda al criterio estatal, y por el contrario, es obligatorio.

Siguiendo el doble estándar verificado en la sentencia cabría preguntarse, entonces, si la Asamblea Nacional como órgano legislativo encargado de cumplir ese extremo de la sentencia ${ }^{27}$, debería adoptar unas reformas a la Constitución (2014), la Ley Electoral (2000)28 y Ley de Amparo (2013) siguiendo el canon interno que regula los derechos políticos de los pueblos indígenas; o el interamericano respecto al control jurisdiccional de las decisiones del CSE en materia electoral. Qué valor tendría el razonamiento de la Corte IDH en una

\footnotetext{
27 De conformidad con el artículo 191 (Cn) la Asamblea Nacional es la única facultada para reformar parcialmente la Constitución y para conocer y resolver sobre la iniciativa de reforma total.

${ }^{28}$ La iniciativa de ley para reformar la Constitución reside en el Presidente de la República y en un tercio de los diputados (arto.191 Cn), y bajo el trámite previsto para la reforma parcial puede ser aprobada con el voto favorable del $60 \%$ de los diputados (arto.194 Cn). Las reformas a las leyes constitucionales también siguen el procedimiento de reforma parcial a la Constitución, pero [...] con la excepción del requisito de las dos legislaturas" (arto. $195 \mathrm{Cn}$ ).
} 
eventual reforma constitucional de las disposiciones declaradas incompatibles con la CADH.

Ciertamente, los artículos 5, 49, 89 y 180 constitucionales y el artículo II.7 del Estatuto de Autonomía de las Regiones de la Costa Caribe (1987) sirvieron como fuente interpretativa de los derechos políticos reconocidos en la CADH. No obstante, las limitaciones indebidas al ejercicio de esos derechos políticos, nacidas de la Ley Electoral (2000), se vieron acogidas ante la inusitada justicia constitucional nicaragüense; y con ello la confirmación del atropello a unos derechos constitucionales sin salvaguarda, cuya protección fue solo posible ante la jurisdicción interamericana ${ }^{29}$. Así, el contenido garantista de las disposiciones internas que sirvieron para interpretar el tratado, terminó recogido bajo el estándar de protección interamericano sobre los derechos de los pueblos indígenas; pero también ampliado y reforzado por la protección judicial de que estaba desprovista en el ámbito doméstico.

Dicho eso, la respuesta esperada del órgano legislativo no sería otra que ajustar las normas impugnadas observando los fundamentos y el canon de protección interamericano establecido en la sentencia; que precisamente subraya el valor interpretativo del derecho interno para ampliar el contenido protector de los derechos políticos recogidos en la CADH. En ese sentido, la fase de implementación de la sentencia no tendría mayores dilemas, pues los derechos políticos de los pueblos indígenas reconocidos en el Derecho nicaragüense han sido subsumidos en el corpus iuris interamericano, que a la vez se ha constituido en un canon de protección para los demás estados, en virtud del efecto irradiador de cosa interpretada de las sentencias interamericanas (Carbonell, 2003).

No obstante, dado la singularidad del caso no se debería desestimar valorar los niveles múltiples de protección de derechos políticos de los pueblos indígenas; en todo caso por la relevancia interpretativa que ha adquirido el derecho interno en este caso concreto. Así, las reformas legislativas deberían tomar en cuenta el Convenio 169 de la OIT sobre pueblos indígenas y tribales en países independientes (1989), del cual Nicaragua es parte, y considerar los criterios de su órgano revisor en este asunto, para ampliar la cobertura de los citados derechos.

${ }^{29}$ Cierto es que la CSJ declaró la inconstitucionalidad de ciertas disposiciones de la Ley Electoral pero no aquellas que afectaban los derechos políticos de los pueblos indígenas. Véase la sentencia No.103 de la CSJ, de 8 de noviembre de 2002. 
En cuanto a la medida para suprimir el carácter inimpugnable de las resoluciones del CSE en materia electoral, es evidente que tal esfuerzo implicaría una reforma parcial a la Constitución, y de las leyes constitucionales citadas, para crear un recurso interno contra aquellas resoluciones. El camino para compatibilizar el texto constitucional con el margen de garantía establecido en la $\mathrm{CADH}$, exige que la Asamblea Nacional tome en cuenta los fundamentos jurídicos del fallo, por una parte, para interrumpir las violaciones vivas $y$, por otra, para impedir la repetición futura de las mismas ${ }^{30}$.

En cuanto al contenido de los mecanismos formales para garantizar el ejercicio de los derechos vulnerados, menos claras resultan las vías que el Estado y las víctimas podrían tomar; toda vez que las posibles soluciones no fueron determinadas en la sentencia y su creación pareció quedar para la etapa de reparaciones. Así, de momento no existe un criterio sobre cómo Nicaragua garantizaría la participación política de YATAMA bajo sus propias formas de organización, usos y costumbres. Aunque algunas propuestas podrían encontrarse en la adopción de un sistema similar a la participación por "suscripción popular", por medio de la cual YATAMA ya había participado en las elecciones regionales antes de que fuese suprimido por la Ley Electoral (2000). Menos problemático resulta la creación del recurso sencillo y rápido para recurrir las decisiones del CSE en materia electoral que, pese a no ser considerado, factiblemente podría traducirse en la ampliación del contenido material del recurso de amparo.

\section{La violación continuada derivada del incumplimiento de la sentencia}

La respuesta del Estado de Nicaragua a las medidas de reparación ordenadas por la Corte IDH ha estado marcada por la falta de voluntad política para cumplir con la sentencia. En términos generales la sentencia se encuentra en estado de incumplimiento en relación a las medidas de reparación positivas o de no repetición, como de aquellas de carácter no pecuniario ${ }^{31}$; que ha sobrevenido a una situación de violación del compromiso internacional de cumplir el fallo contenido en el artículo 68.I de la CADH.

\footnotetext{
${ }^{30}$ Cierto es que el artículo 45 constitucional reconoce el derecho constitucional a ser amparado ante posibles violaciones a los derechos constitucionales, pero su ejercicio sigue limitado por el párrafo último del artículo 173 constitucional.

${ }^{31}$ Infra Nota 22.
} 
En cuanto al análisis del cumplimiento de las medidas legislativas aquí propuesto, es de destacar que pese a reformas constitucionales que han tenido lugar desde la publicación de la sentencia, en ninguna se ha planteado la adopción de las citadas medidas legales. Es así, que el acatamiento de las medidas legislativas se mantuvo al margen de la reforma a la Ley Electoral (2000) aprobada por la Asamblea Nacional en el 201232, en cuya sede el asunto no fue siquiera parte de la discusión parlamentaria; pese a que tal circunstancia fue mencionada por YATAMA $^{33}$. La misma suerte tuvo la reforma parcial a la Constitución Política aprobada en el 201434, bajo la cual no se suprimió el cuestionado artículo que establece la inimpugnabilidad de las decisiones en materia electoral del CSE.

Cierto es que las reformas electorales aprobadas en el 2012 abordaron diversos aspectos relacionados a la participación política, pero no introdujeron ningún cambio sustancial respecto al marco legal impugnado y, por el contrario, sólo derogaron los artículos 65.9 y 77.7 de la Ley Electoral (2000) ${ }^{35}$, que con anterioridad habían sido declarados inconstitucionales en la sentencia No.103 de la CSJ, de 8 de noviembre de $2002^{36}$. Aun así, no se suprimió el párrafo segundo del artículo 82 de la Ley Electoral (2000), declarado incompatible con la $\mathrm{CADH}^{37}$. En esos términos, las reformas legales sólo derogaron los preceptos declarados inconstitucionales por la CSJ, pero no los declarados "inconvencionales" por la Corte IDH.

${ }^{32}$ Recogida en la Ley No. 790, aprobada el 15 de mayo de 2012 y publicada en la Gaceta No. 95 del 23 de Mayo de 2012.

${ }^{33}$ Véase las intervenciones del diputado Brooklyn Rivera Bryan en la discusión de las reformas a la Ley Electoral (2000), realizado en el Sesión Ordinario No.2 de la Asamblea Nacional, del 2 de mayo de 2012(Vigésima octava legislatura). Disponible en la página Web de la Asamblea Nacional www.asamblea.gob.ni

${ }^{34}$ Véase la Ley No. 854 Ley de Reforma Parcial a la Constitución Política de la República de Nicaragua publicada en la Gaceta Diario Oficial No.26, el 10 de Febrero de 2014.

${ }^{35} \mathrm{Su}$ derogación se considera como el único aspecto positivo de cara al cumplimiento del fallo interamericano, pero deja invariable la situación continuada de violación respecto a las demás normas "inconvencionales" no derogadas.

${ }^{36}$ Así fue planteado en la exposición de motivos de la iniciativa de reforma a la Ley Electoral (2000) presentado por el Presidente de la República. Disponible en la página Web de la Asamblea Nacional www.asamblea.gob.ni

${ }^{37}$ Lo cierto es que la nueva disposición dejó intacto el texto anterior del artículo 82 y solo adicionó el deber de los partidos políticos y alianzas de "presentar en sus listas de candidatos un cincuenta por ciento de hombres y un cincuenta por ciento de mujeres ordenados de forma equitativa y presentada de manera alterna" en las elecciones municipales, de diputados y diputadas de la Asamblea Nacional y el Parlamento Centroamericano. 
La posición del Estado de Nicaragua frente a las medidas de reparación establecidas ha tenido criterios divergentes que la han distanciado de experiencias anteriores ante la Corte IDH. El propio tribunal regional hizo mención de ello al recordarle al Estado de Nicaragua que en "la sentencia del caso de la Comunidad Mayagna (Sumo) Awas Tingni asumió una serie de compromisos dirigidos a la ejecución del único punto resolutivo pendiente de cumplimiento, lo cual resultó en el cumplimiento de la totalidad de la sentencia y el archivo del caso"38. Sin embargo, respecto al cumplimiento de la sentencia Yatama, el Estado se ha mostrado reticente a cumplir la sentencia e, incluso, a atender la obligación de informar sobre el proceso mismo de implementación. Por ello que en la última resolución sobre la supervisión del cumplimiento de la sentencia, la Corte IDH recodase al Estado de Nicaragua que desde el 6 de diciembre de 2008 no ha presentado las observaciones sobre las medidas adoptadas para cumplir con la sentencia, ni ha acudido a las audiencias privadas, pese a las múltiples prórrogas concedidas por el tribunal ${ }^{39}$.

Así las cosas, tal situación ha perpetuado en el tiempo las circunstancias legales que dieron origen al caso, cuyos efectos han discurrido en una situación continuada de violación de derechos. En primer lugar, porque la lesión al derecho a la participación política y al derecho a un recurso efectivo contra las decisiones del CSE sigue viva, como consecuencia del incumplimiento de las medidas legales establecidas. Segundo, porque las disposiciones declaradas contrarias a la CADH siguen produciendo efectos ininterrumpidos en el tiempo al no haber sido abolidos mediante las medidas legales pertinentes; $y$ por último, tercero, porque los efectos perpetuados en el tiempo de la normativa inconvencional han trascendiendo el caso concreto y afecta a todos los actores políticos que han estado inmersos en los sucesivos procesos electorales, donde dicha disposiciones legales han sido aplicadas.

\footnotetext{
${ }^{38}$ Para ampliar más sobre el cumplimiento de la citada sentencia véase la resolución de la Corte IDH sobre la supervisión de cumplimiento de sentencia Yatama vs. Nicaragua, de 22 de Agosto de 2013, Considerando No.13.

${ }^{39}$ Idem. Considerandos 9-19.
} 


\section{El control interno de convencionalidad como respuesta al incumplimiento de la sentencia interamericana}

La obligación de todo Estado parte de la CADH de cumplir con sus obligaciones internacionales en el área de los derechos humanos atiende, también, a la idea de que las autoridades y jueces materialicen aquellos compromisos en el ejercicio de sus funciones, respondiendo de forma coherente y efectiva en situaciones concretas donde los derechos humanos reconocidos puedan verse afectados. En esa lógica, la Corte IDH ha establecido una serie de criterios jurisprudenciales para desentrañar el contenido sustancial de los artículos I.I y 2 de la CADH, señalando para tal efecto que:

"[...] cuando un Estado ha ratificado un tratado internacional como la Convención Americana, sus jueces, como parte del aparato del Estado, también están sometidos a ella, lo que les obliga a velar porque los efectos de las disposiciones de la Convención no se vean mermadas por la aplicación de leyes contrarias a su objeto y fin, y que desde un inicio carecen de efectos jurídicos. En otras palabras, el Poder Judicial debe ejercer una especie de "control de convencionalidad" entre las normas jurídicas internas que aplican en los casos concretos y la Convención Americana sobre Derechos Humanos. En esta tarea, el Poder Judicial debe tener en cuenta no solamente el tratado, sino también la interpretación que del mismo ha hecho la Corte Interamericana, intérprete última de la Convención Americana" (Almonacid Arellano y otros v. Chile, 2006, párr. 124) ${ }^{40}$.

Bajo esos términos se transitó de la analogía constitucional de la función judicial de la Corte IDH con el control concentrado de constitucionalidad, a una proyección interna del llamado "control de convencionalidad" que la doctrina ha

\footnotetext{
${ }^{40}$ Corte IDH, Almonacid Arellano y otros v. Chile, párr. 124. Aunque cierto es que fue el ex juez Sergio García Ramírez quien introdujo aquella categoría en su voto razonado en la sentencia Myrna Mack Chang vs. Guatemala. Más tarde reiterado en su voto razonado en la sentencia Tibi v. Ecuador, entencia de 7 de septiembre de 2004, equiparando la función judicial de la Corte Interamericana con la de los tribunales constitucionales en el Control de Constitucionalidad. Así sostuvo: [...]si los tribunales constitucionales controlan la "constitucionalidad", el tribunal internacional de derechos humanos resuelve acerca de la "convencionalidad" de esos actos" (párr.3). (Hitters, 2009; Castilla, 2011).
} 
denominado "control difuso de convencionalidad"4l. En este escenario, el habilitado para ejercer aquella función jurisdiccional de matriz internacional no sería la Corte IDH, sino los jueces nacionales, cualquier órgano de los poderes públicos que ejerza funciones jurisdiccionales (Vélez Loor vs. Panamá, 2010, párr.287), los "órganos vinculados a la administración de justicia en todos los niveles" (Cabrera García y Montiel Flores vs. México, 2010, párr.225) o "cualquier autoridad pública y no sólo del Poder Judicial" (Gelman vs. Uruguay, 20II, párr. 239).

En otras palabras, los jueces internos verificarían la compatibilidad de los actos y las normas internas (leyes, decretos, ordenanzas, actos administrativos), incluso la Constitución Política, con la Convención Americana y demás instrumentos interamericanos; tomando en cuenta la jurisprudencia interamericana y las normas ius cogens reconocidos en aquella (Hitters, 2009). El juez nacional se convertiría "en un primer y auténtico guardián de la Convención Americana de sus Protocolos adicionales (eventualmente de otros instrumentos internacionales) y de la jurisprudencia de la Corte IDH que interpreta dicha normatividad"42.

A diferencia del control jurisdiccional ejercido por la Corte Interamericana, aquí los jueces internos o la autoridad legitimada para aplicarlo no tiene claro los contornos de tal actividad, toda vez que, de acuerdo con Sagües (20II) el "control de convencionalidad" no aparece expresamente en la CADH y es producto de una interpretación mutativa por adición del tratado. Este se deriva de las obligaciones genéricas contraídas por los Estados con la CADH (arto. I.I y 2), el principio de buena fe consagrado en el artículo 27 de la Convención de Viena sobre Derechos de los Tratados (Gómes Lund y otros (Guerrilha do Araguaia) vs. Brasil, 2010, párr. 176), la obligatoriedad de sus sentencias (arto.68.I $\mathrm{CADH}$ ) y la imposibilidad de los Estados de alegar razones de orden interno para no cumplir con sus compromisos, también recogido en el 27 de la citada Convención de Viena.

\footnotetext{
${ }^{41}$ Véase también los votos razonados de los jueces Sergio García Ramírez y Antonio A. Cançado Trindade a la sentencia Trabajadores Cesados del Congreso (Aguado Alfaro y otros) vs. Perú; y el voto razonado de juez ad hoc Eduardo Ferrer Mac-Gregor a la sentencia Cabrera García y Montiel y Flores vs. México. También retomado por Sagües (2010), Ferrer Mac-Gregor (2010) y García Ramírez, (2011).

${ }^{42}$ Véase el voto razonado del juez ad hoc Eduardo Ferrer Mac-Gregor a la sentencia Cabrera García y Montiel y Flores vs. México. párr. 24.
} 
De acuerdo con aquellos postulados todo juez interno está obligado a aplicar de forma preferente, si es el caso, una norma internacional sobre una norma interna, independientemente de su rango jerárquico; con el objeto de velar porque los efectos de la Convención no se vean mermados por la aplicación de leyes contrarias a su fin y objeto; con lo que se vendría abajo el axioma de que ninguna norma está por encima de la Constitución (arto.182 Cn), como se señaló anteriormente. De tal forma que la Corte IDH ha interpretado que "los órganos del Poder Judicial deben ejercer no sólo un control de constitucionalidad, sino también de convencionalidad" (Trabajadores Cesados del Congreso (Aguado Alfaro y Otros) vs. Perú, párr. 128.), lo que presupone la existencia de un juez habilitado para un "doble control”, según Sagües (20l0).

Según los criterios de la Corte IDH, la aplicación de dicha figura es ex officio ${ }^{43}$, por lo que el ámbito de valoración de conflictos normativos pueden ser consideradas, aun sin las partes no las han invocado; no obstante, siempre adecuado a los "presupuestos formales y materiales de admisibilidad y procedencia de ese tipo de acciones", como lo señalara en Trabajadores Cesados del Congreso (Aguado Alfaro y Otros) vs. Perú.

Es claro que el "control difuso de convencionalidad" enfrenta muchos retos, especialmente por la falta de regulación interna y la vaguedad sobre los efectos legales de las sentencias internas que declaren la "inconvencionalidad" de una norma (Castilla, 2013); así como por las complejidades que puede derivar su aplicación en sistemas concentrados de constitucionalidad, donde no todos los jueces pueden declarar la inaplicabilidad de una norma constitucional; o en sistemas legales donde un órgano administrativo u autoridad municipal no legitimado constitucionalmente pueda inaplicar o actuar contra una disposición suprema ${ }^{44}$. En ese sentido, se está en desacuerdo de que tal figura jurídica pueda

${ }^{43}$ Sobre este asunto véase las sentencias Trabajadores Cesados del Congreso (Aguado Alfaro y Otros) vs. Perú (2006, párr. 128), La Cantuta vs. Perú (2006, párr,173), Boyce y otros vs. Barbados (2007, párr.78), Heliodoro Portugal vs. Panamá (2008, párr.180), Radilla Pacheco vs. México (2009, párr.339), Manuel Cepeda Vasgas vs. Colombia (2010, párr.307), Comunidad Indígena Xakmok Kásek vs. Paraguay (2010, párr. 311), Ibsen Cárdenas e Ibsen Peña vs. Bolivia (2010, párr. 202), Fernández Ortega y otros vs. México (2010, párr. 236), Rosendo Cantú y otra vs. México (2010, párr. 219); Gelman vs. Uruguay (2011, párrs. 193 y 239).

${ }^{44}$ Precisamente la Constitución de Nicaragua (arto. 183) ha establecido para tal efecto que "Ningún Poder del Estado, organismo de gobierno o funcionario tendrá otra autoridad, facultad o jurisdicción que las que le confiere la Constitución Política y las leyes de la República". 
tener una aplicación automática en la diversidad de sistemas jurídicos en que rige.

No obstante, en el caso particular de la sentencia que nos ocupa, tal figura puede tener cierta utilidad práctica debido a la favorable configuración del sistema de control de constitucionalidad nicaragüense, y el valor jurídico interno de la CADH, para inaplicar las normas declaradas "inconvencionales". En todo caso, por la situación concreta derivada del incumplimiento de la sentencia y la existencia de mecanismos procesales para tal fin.

Así, pues, si se considera que todas las autoridades nicaragüenses están obligadas a tomar en cuenta los tratados internacionales y la jurisprudencia interamericana para resolver casos propios de su jurisdicción, que pueda afectar los derechos humanos; es incuestionable que la Asamblea Nacional, al momento de legislar; el CSE, cuando decide sobre materia electoral; la CSJ, cuando resuelve asuntos de su jurisdicción; se vean compelidos a velar porque los efectos de las disposiciones de la CADH no se vea mermado por la aplicación de leyes contrarias a su objeto y fin; más aún, si tales leyes han sido ya declaradas incompatibles con el tratado en una sentencia contra el mismo Estado45.

En efecto, la obligación de la Asamblea Nacional de cara al fallo sería para obrar en sentido positivo, esto es, legislar para revertir los efectos de las normas "inconvencionales"; como en sentido negativo, que se traduciría en la obligación de abstenerse de legislar para perpetuar y acentuar las intromisiones indebidas al ejercicio de los derechos concernidos, como afectar otros derechos y libertades protegidos en la Constitución y los tratados internacionales.

Sin embargo, ante la imposibilidad política de que la Asamblea Nacional pueda hacer efectivas las reformas legislativas establecidas por la Corte IDH, se espera que bajo la figura del "control interno de convencionalidad" la CSJ puedan tener un rol determinante en la inaplicabilidad de la normativa 'inconvencional' aún vigente. En ese sentido, la decisión de inaplicar aquellas disposiciones constitucionales no sucedería en el contexto del cumplimiento de las medidas

\footnotetext{
${ }^{45}$ En efecto, en la sentencia de supervisión de cumplimiento de sentencia Gelman y otros v. Uruguay, de 20 marzo de 2013 (párr. 67 y ss), la Corte IDH sostuvo la aplicabilidad del "control de convencionalidad" por virtud de los efectos de cosa juzgada internacional de una sentencia dictada contra el Estado concernido, como por efectos de cosa interpretada para Estados no parte de la litis (Pelayo, 2013).
} 
de reparación 46 , sino en el ejercicio de un ajustado "control de convencionalidad", por la declaración de 'inconvencionalidad' que precede y el incumplimiento mismo de las medidas legales ordenadas.

Lo anterior podría verse favorecido por la mixta configuración del control constitucional en Nicaragua: concentrado y difuso. Esta dualidad aliviaría, en parte, la conflictividad resultante de la obligación deducida por la Corte IDH de inaplicar una norma constitucional, estimada "inconvencional”, indistintamente del sistema de control de constitucionalidad en que dicha acción pueda tener lugar.

La Constitución (2014) establece que el control de constitucionalidad recae en el sistema judicial representado por la CSJ47 y es activado por medio del recurso por inconstitucionalidad (arto. 187), de amparo (arto. 188), de exhibición personal (arto. 189) y habeas data (arto.190.1), conflicto de competencia y constitucionalidad entre los poderes del Estado (arto.190.2) y el control de constitucionalidad en el caso concreto (arto. 190.3) ${ }^{48}$. Este último habilita a toda autoridad judicial (jueces locales, de distrito y del tribunal de apelación) que conozca de un caso, para declarar la inaplicabilidad de una norma al caso concreto de cuya validez depende el fallo. A los anteriores habría que agregar el recurso por conflictos de constitucionalidad entre el Gobierno Central y los Gobiernos Municipales y de las Regiones Autónomas de la Costa Caribe (arto. 190.4).

Así, entonces, todos los jueces se convierten en garantes de la supremacía constitucional, en cuyo ejercicio también examinaran la 'convencionalidad' de las normas internas, incluidas las propias disposiciones constitucionales; lo cual, en definitiva, terminaría cuestionando la declaración de preeminencia del texto constitucional, si la CADH se termina imponiendo sobre la Constitución. En tales circunstancias, habría que hacer una lectura más amplia de tal cláusula en conjunción con el valor constitucional que ostenta dicho tratado (arto.46 Cn), como ya se ha explicado, cuyos lazos materiales vendrían a construir una excepción a dicha cláusula.

\footnotetext{
${ }^{46}$ En este sentido, hay que recordar que la sentencia estableció como medidas de reparación la adopción de medidas legales cuyo mecanismo de cumplimiento está previsto por vía legislativa y no jurisdiccional.

${ }^{47}$ Artículos 164 numerales 2, 3, 4, 12, 13 de la Constitución nicaragüense.

${ }^{48}$ Y regulado en el artículo 5 de la Ley Orgánica del Poder Judicial (1998) y los artículos 20, 21 y 22 de la Ley de Amparo (2013).
} 
Así, pues, la CSJ y toda autoridad judicial no se verían impedidos de examinar una norma interna a la luz de la CADH y demás tratados interamericanos, si para ello se procede bajo las regulaciones y procedimientos previstos para el control de constitucionalidad; en una suerte de un "control de convencionalidad" subsumido en el control de constitucionalidad. El problema que podría surgir sería respecto a los efectos de la sentencia que declare la 'inconvencionalidad' de una norma constitucional, al no existir ninguna disposición interna que regule tal materia. Sin embargo, esto podría encontrar una respuesta en los efectos previstos para las sentencias que declaran una inconstitucionalidad, en virtud de la posición del tratado.

Ahora bien, si se considera el estatus constitucional de la CADH en el derecho nicaragüense, resulta evidente intuir la inconstitucionalidad de las normas declaradas "inconvencionales" en el fallo interamericano; no obstante, tal apreciación no es de aplicación automática pues se sabe que la inconstitucionalidad de una norma solo puede ser declarada por la CSJ ${ }^{49}$. En ese sentido, para declarar la inaplicabilidad de las disposiciones internas "inconvencionales" aún vigentes, bastaría con aplicar un "control interno de convencionalidad" a partir de los criterios de la Corte IDH en la aludida sentencia, bajo los mecanismos procesales internos para tal fin.

En ese supuesto, la activación del mecanismo de control de jurisdiccional interno se estima bajo una acción de inconstitucionalidad, en cuyo caso cabría una especie de trasposición de los criterios interamericanos que preceden a la jurisdicción interna. Otro mecanismo que podría tener algún acierto sería el recurso de amparo (art.188 Cn), especialmente si se ejerce en contra de las disposiciones declaradas contrarias a la $\mathrm{CADH}$; o cuando una resolución, acción u omisión del CSE viole o trate de violar los derechos, mediante la aplicación de las normas "inconvencionales".

Pese a que la misma falta de avenencia política ha conducido al estado actual de incumplimiento de las medidas legislativas, y que ésta misma pueda resultar decisiva para evitar que cualquiera de los mecanismos procesales anteriores pueda prosperar de forma exitosa; ello no desdice la posibilidad de que el effect utile de la CADH pueda hacerse valer en los supuestos procesales mencionados; como tampoco que la respuesta del Estado de Nicaragua frente al fallo interamericano involucra a todas las autoridades y jueces, aunque las medidas de

\footnotetext{
${ }^{49}$ Por intermediación del recurso de inconstitucionalidad, que puede ser ejercido por cualquier ciudadano (arto.187 Cn).111
} 
reparación positivas estén enfocadas a la reforma de algunas disposiciones constitucionales.

\section{Conclusiones}

El conflicto normativo vislumbrado por la Corte IDH entre las disposiciones constitucionales y la CADH en el caso Yatama vs. Nicaragua, deja constancia de que el control jurisdiccional supranacional efectuado sobre las normas internas no se vio afectado por su jerarquía en el sistema de fuentes; pues las normas constitucionales impugnadas son consideradas como un hecho más a ser probado en la jurisdicción interamericana. En ese sentido, el "control de convencionalidad" practicado por dicho tribunal asume una categoría "supraconstitucional".

En esos términos, se colige que la Constitución está supeditada a la correspondencia de su contenido con los tratados internacionales de derechos humanos ratificados por Nicaragua; en caso contrario una norma constitucional puede ser declarada contraria a la CADH por la Corte IDH, por ejemplo, por no superar el examen de compatibilidad bajo el denominado "control de convencionalidad", como se ha visto en la sentencia del caso Yatama.

Desde otro ángulo, la apreciación del control jurisdiccional de matriz internacional también tendría cabida en el ámbito interno, si la autoridad pública - juez interno llamado a practicar el "control interno de convencionalidad", declara inaplicable una norma constitucional en conflicto con la CADH; o cualquier otro tratado interamericano ratificado por Nicaragua"; por intermediación del principio pro homine o de una sentencia interamericana contra el Estado mismo, por ejemplo. En tales supuestos, tampoco tendría mayor relevancia la jerarquía normativa impugnada, o en conflicto, ante la inexorable obligación internacional y la supremacía del tratado. En virtud de la configuración del control de constitucionalidad en Nicaragua, y el valor jerárquico de la $\mathrm{CADH}$, la procedencia de tal mecanismo se vería allanado por la vía constitucional.

La situación actual de incumplimiento de la sentencia Yatama podría encontrar en el "control interno de convencionalidad", una solución práctica y alternativa a las medidas legislativas establecidas por la Corte IDH y paralizadas en la Asamblea Nacional. En este escenario, la CSJ podría verse habilitada para inaplicar y declarar la inaplicabilidad de las disposiciones "inconvencionales" de 
la Ley Electoral (2000) y la Constitución (2014), de conformidad con los criterios establecidos en la sentencia interamericana. Con el objetivo de interrumpir los efectos perpetuados en el tiempo de las disposiciones legales que dieron origen al caso, que a día de hoy se traduce en una violación continuada de derechos.

\section{Referencias Bibliográficas}

ABREU BURELLI, A. (1999). El proceso ante la Corte Interamericana de Derechos Humanos. En México y las Declaraciones de Derechos Humanos (pp. 119-140). México/UNAM/Corte Interamericana de Derechos Humanos.

BAZÁN, Víctor. (20I2). El Control de Convencionalidad: incógnitas, desafíos y perspectivas. En BAZÁN Víctor y NASH Claudio (ed.). Justicia Constitucional y Derechos Fundamentales. El Control de Convencionalidad (pp. 17-56). Chile, Centro de Derechos Humanos. Universidad de Chile.

BREWER-CARÍAS, A. R. (20I2). El control de convencionalidad, con particular referencia a la garantía del derecho a la protección judicial mediante un recurso sencillo, rápido y efectivo de amparo de los derechos humanos. Seminario sobre El control de convencionalidad y su aplicación organizado por la Sala Constitucional de la Corte Suprema de Justicia de Costa Rica, San José, Costa Rica, 28 septiembre, (paper).

CASTILLA, Karlos. (201 I). El Control de Convencionalidad: un nuevo debate en México a partir de la sentencia del caso Radilla Pacheco. Anuario Mexicano de Derecho Internacional. Vol. XI. pp. 593-624.

CASTILLA, Karlos. (2013). ¿Control Interno o Difuso de Convencionalidad? Una mejor idea: la garantía de los tratados. Anuario Mexicano de Derecho Internacional. Vol. XIII, pp. 5I-97.

REMOTTI CARBONELL, J. C. (2003). La Corte interamericana de derechos humanos. Estructura, funcionamiento y jurisprudencia. Instituto Europeo de Derecho, Barcelona. p.272.

GARCÍA RAMÍREZ, Sergio. (20II). El control interno de convencionalidad. Revista del Instituto de Ciencias Jurídicas de Puebla, (28), Año V, julio-diciembre, pp. I23-I59.

GARCÍA ROCA, J., NOGUERA ALCALÁ, et.al. (20I2). La comunicación entre ambos sistemas y las características ' . .... SÁNCHEZ, P. A. et.al. (ed) ISSN 1993-4505 / No. 18, 2015 / Cárdenas Velásquez Derechos Humanos (pp.66-10, . . .........., ... ...........

FERRER MAC-GREGOR, Eduardo. (2010). El Control Difuso de Convencionalidad en el Estado Constitucional. En FIX-ZAMUDIO, Héctor y VALADÉS, Diego (coords.). Formación y perspectiva del Estado mexicano (Pp. 15I-188). México, El Colegio Nacional-UNAM.

FERRER MAC-GREGOR, E. y PELAYO MOLLER, C. M. (20I2). El deber de adoptar disposiciones de derecho interno. Análisis del artículo $2^{\circ}$ de la Convención Americana sobre Derechos Humanos y su impacto en el orden jurídico nacional. En PÉREZ JOHNSTON, R., RODRÍGUEZ MANZO, G. y SILVA DÍAZ, R. A (coords). Derecho Internacional de los Derechos Humanos (pp. 53-99). México, Porrúa- Centro de Investigación e Informática Jurídica. 
HITTERS, Juan Carlos. (2009). Control de Constitucionalidad y Control de Convencionalidad. Comparación (criterios fijados por la Corte Interamericana de Derechos Humanos). Centro de Estudios Constitucionales de Chile, Universidad de Talca, (2), Año 7, pp. 109-128.

HITTERS, Juan Carlos (2006). Incidencia de la jurisdicción de los tribunales supranacionales. XX Jornadas Iberoamericanas de Derecho Procesal, Málaga-España, 25 a 27 de octubre, (paper).

PELAYO MÖLLER, C.M. (20I3). El surgimiento y desarrollo de la doctrina de "Control de Convencionalidad" y sus implicaciones en el Estado Constitucional. (En línea), Recuperado el 9 de junio de 2013 de http://www.miguelcarbonell.com/docencia/El_surgimiento_y_desarrollo_de_la_d octrina_de_Control_de_Convencionalidad_y_sus_implicaciones.shtml

SAGÜES, N. P. (20II). El control de convencionalidad en el sistema interamericano y sus anticipos en el ámbito de los derechos económico-sociales. Concordancias y diferencias con el sistema europeo. En VON BOGDANDY, Armin, et. al., Construcción y papel de los derechos sociales fundamentales. Hacia un ius constitucionale commune en América Latina (pp. 381-417) México, UNAM-Max Planck Institut-Instituto Iberoamericano de Derecho Constitucional.

SAGÜES, N. P. (2010). Obligaciones internacionales y control de convencionalidad. Centro de Estudios Constitucionales de Chile. Universidad de Talca (I), Año 8. Pp. II7-136.

Legislación nacional

Asamblea Nacional (1998). Ley No. 260. Ley Orgánica del Poder Judicial.

Publicada en La Gaceta Diario Oficial No. 137, del 23 de Julio del 1998. Nicaragua.

Asamblea Nacional. (20I3). Ley No. 83I. Ley de reformas y adiciones a la Ley

No. 49. Ley de Amparo. Publicada en La Gaceta Diario Oficial No. 29, del I 4 de febrero del 20 I3. Nicaragua.

Asamblea Nacional. (2012). Ley No. 33I. Ley Electoral con sus reformas incorporadas. Publicado en La Gaceta Diario Oficial No. 168, del 4 de Septiembre de 2012. Nicaragua

Asamblea Nacional. (20I4). Ley No. 854. Ley de Reforma Parcial a la Constitución Política de la República de Nicaragua. Publicada en La Gaceta Diario Oficial No.26, del 10 de Febrero de 2014. Nicaragua

Asamblea Nacional. (20I2). Ley No. 790. Ley de reforma a la Ley No. 33I. Ley Electoral. Publicada en La Gaceta Diario Oficial No. 95, del 23 de Mayo de 2012. Nicaragua.

Jurisprudencia Interamericana

Corte IDH, Genie Lacayo vs. Nicaragua (Fondo, Reparaciones y Costas), sentencia de 29 de enero de 1997. Serie C No. 30.

Corte IDH, Comunidad Mayagna (Sumo) Awas Tingni vs. Nicaragua (Fondo,Reparaciones y Costas), sentencia de 31 de agosto de 200I.Serie C No. 79.

Corte IDH, Yatama vs. Nicaragua (Excepciones Preliminares, Fondo,Reparaciones y Costas), sentencia de 23 de junio de 2005. Serie C No. 127.

Corte IDH, Almonacid Arellano y otros vs. Chile (Excepciones Preliminares, Fondo, Reparaciones y Costas), sentencia de 26 de septiembre de 2006. Serie C No. 154. 
Corte IDH, Tibi vs. Ecuador (Excepciones Preliminares, Fondo, Reparaciones y Costas), sentencia de 7 de septiembre de 2004. Serie C No. II4.

Corte IDH, Vélez Loor vs. Panamá (Excepciones Preliminares, Fondo, Reparaciones y Costas), sentencia de 23 de noviembre de 2010 Serie C No. 218.

Corte IDH, Cabrera García y Montiel Flores vs. México (Excepción Preliminar, Fondo, Reparaciones y Costas), sentencia de 26 de noviembre de 2010 Serie C No. 220.

Corte IDH, Gelman vs. Uruguay (Fondo y Reparaciones), sentencia de 24 de febrero de 20II. Serie C No.221.

Corte IDH, Gómes Lund y otros (Guerrilha do Araguaia) vs. Brasil (Excepciones

Preliminares, Fondo, Reparaciones y Costas), sentencia de 24 de noviembre de 2010. Serie C No. 219.

Corte IDH, Trabajadores Cesados del Congreso (Aguado Alfaro y Otros) vs. Perú (Excepciones Preliminares, Fondo, Reparaciones y Costas), sentencia de 24 de Noviembre de 2006. Serie C No. 158.

Corte IDH, La Cantuta vs. Perú (Fondo, Reparaciones y Costas), sentencia de 29 de noviembre de 2006. Serie C No. 162.

Corte IDH, Boyce y otros vs. Barbados (Excepción Preliminar, Fondo, Reparaciones y Costas), sentencia de 20 de noviembre de 2007. Serie C No. 169.

Corte IDH, Heliodoro Portugal vs. Panamá (Excepciones Preliminares, Fondo, Reparaciones y Costas), sentencia de 12 de agosto de 2008. Serie C No. 186.

Corte IDH, Radilla Pacheco vs. México (Excepciones Preliminares, Fondo, Reparaciones y Costas), sentencia de 23 de Noviembre de 2009. Serie C No. 209.

Corte IDH, Manuel Cepeda Vasgas vs. Colombia (Excepciones Preliminares, Fondo, Reparaciones y Costas), sentencia de 26 de mayo de 20I0. Serie C No. 213.

Corte IDH, Comunidad Indígena Xakmok Kásek vs. Paraguay (Fondo, Reparaciones y Costas), sentencia de 24 de agosto de 20I0. Serie C No. 214.

Corte IDH, Ibsen Cárdenas e Ibsen Peña vs. Bolivia, (Fondo, Reparaciones y Costas), sentencia de I de septiembre de 2010 Serie C No. 217.

Corte IDH, Fernández Ortega y otros vs. México (Excepción Preliminar, Fondo, Reparaciones y Costas), sentencia de 30 de agosto de 2010. Serie C No. 215.

Corte IDH, Rosendo Cantú y otra vs. México (Excepción Preliminar, Fondo, Reparaciones y Costas), sentencia de 31 de agosto de 2010 Serie C No. 216.

Corte IDH. Propuesta de Modificación a la Constitución Política de Costa Rica Relacionada con la Naturalización. (Opinión Consultiva OC-4/84) del 19 de enero de 1984. Serie A No. 4. 